\title{
Basal Insulin Intensification in Patients with Type 2 Diabetes: A Review
}

Jerry Meece

Received: December 6, 2017 / Published online: March 24, 2018

(C) The Author(s) 2018

\section{ABSTRACT}

As the number of people living with type 2 diabetes (T2D) continues to rise, managing their complex needs presents an increasing challenge to physicians. While treatment guidelines provide evidence-based guidance, they are not prescriptive-rather they emphasize individualization of management based on a patient's clinical needs and preferences. Physicians, therefore, need to be fully aware of the advantages and disadvantages of the multiple and increasing treatment options available to them at each stage of the disease. The progressive nature of T2D means that treatment with basal insulin will become inevitable for many patients, while for some patients basal insulin alone will eventually be insufficient for maintaining glycemic targets. Recent guidelines recommend two basic approaches for intensifying basal insulin: the use of rapid-acting insulin, either as additional prandial injections or as part of premix (biphasic) insulin; and the addition of glucagon-like peptide-1 receptor agonists (GLP-1 RAs) to the insulin therapy, which

Enhanced content To view enhanced content for this article go to https://doi.org/10.6084/m9.figshare. 5928823 .

\section{J. Meece ( $\square)$}

Clinical Services, Plaza Pharmacy and Wellness

Center, Gainesville, TX, USA

e-mail: jmeece12@cooke.net can be administered via subcutaneous injection once or twice daily, or weekly depending on formulation. More recently, two fixed-ratio combinations of basal insulin and a GLP-1 RA that allow for once-daily dosing have been approved. Each of these approaches has potential benefits and drawbacks, particularly in terms of risk for hypoglycemia, weight change, convenience, and side effects. Understanding these differences is central to guiding patient and physician choice. This article discusses the rationale, advantages, disadvantages, and implementation of currently available strategies for basal insulin treatment intensification in patients with T2D.

Funding: Sanofi US, Inc.

Keywords: Basal insulin; Diabetes type 2; Fixed-ratio combinations; Glucagon-like peptide-1 receptor agonist; Treatment intensification

\section{INTRODUCTION}

The number of people living with type 2 diabetes (T2D) is ever-growing. In 2017, it has been estimated that almost 425 million adults worldwide had diabetes, and this is projected to increase to 628 million by 2045 [1]. This alarming figure is a result of the aging population, which is more likely to develop T2D, 
together with population-wide lifestyle changes, and also reflects the fact that T2D is being diagnosed earlier and, with advances in management strategies, patients are living longer [1]. Managing the complex needs of patients with long-standing T2D is therefore an increasingly common clinical challenge for primary healthcare practitioners. Current treatment guidelines provide evidence-based guidance for T2D management, but they are not prescriptive and emphasize the importance of individualization of T2D management based on a patient's clinical needs and preferences $[2,3]$. If physicians are to achieve this, they need to be fully aware of the advantages and disadvantages of the multiple treatment options and strategies available to them at each stage of the disease.

T2D is a progressive disease, and although some patients may manage it with oral medications, most will eventually need to use insulin to achieve glycemic control. Insulin treatment is usually initiated when patients are no longer meeting glycemic targets on combination therapy using oral drugs, or present with a glycated hemoglobin $\mathrm{A}_{1 \mathrm{c}}(\mathrm{HbA1c})$ level of $>9.0 \%$ with symptomatic hyperglycemia [3]. Guidelines continue to be revised however, and basal insulin therapy is now often used much sooner and frequently in combination with oral agents or glucagon-like peptide-1 receptor agonists (GLP-1 RAs), rather than postponing insulin therapy until lifestyle modifications and oral agent treatment has failed [2, 3]. Guidelines for initial insulin therapy are straightforward. The first step for most patients is the addition of a long-acting basal insulin to oral therapy to control fasting plasma glucose (FPG) levels. In general, insulin analogs are favored over neutral protamine Hagedorn (NPH) insulin, largely because of their better hypoglycemic profile due to their flat pharmacokinetic curve [2, 3]; however, NPH insulin is associated with markedly lower costs and remains widely used in some settings, such as in resource-limited countries [4]. Many patients will successfully achieve and maintain glycemic goals on these regimens, but the disease of other patients may progress to the point at which basal insulin alone is insufficient, and these latter patients will require additional therapeutic support to control postprandial glucose (PPG) levels.
Managing patients who do not achieve glycemic goals despite uptitration of basal insulin provides a particular challenge, with a number of available options. Until recently, the recommended strategy for intensifying insulin therapy was the addition of rapid-acting insulins (RAIs) to the treatment regimen, either as additional prandial injection or as part of a premixed insulin formula. However, over recent years combining a GLP-1 RA with basal insulin has been shown to provide equal or slightly superior efficacy to the addition of prandial insulin, with a beneficial effect on weight and less hypoglycemia, as well as reduced regimen complexity [5-9]. Based on this finding, the most recent 2018 recommendations from the American Diabetes Association state that compared with basal-plus insulin, "basal insulin plus GLP-1 RAs are associated with less hypoglycemia and with weight loss instead of weight gain but may be less tolerable and have a greater cost" [2].

Treatment guidelines, therefore, give two potential approaches for intensifying insulin therapy: the addition of a RAI, either as an additional prandial injection or as part of a premixed insulin formula; or the addition of a GLP-1 RA (Fig. 1). In review I discuss the rationale and implementation of these two approaches and consider their advantages and disadvantages.

This review article is based on previously conducted studies and does not contain studies with human participants or animals performed by any of the authors.

\section{THE PROBLEM OF OVER- BASALIZATION}

Uptitrating basal insulin is no longer having an HbA1c-lowering effect, while higher insulin doses mean greater risk of weight gain and hypoglycemia. Treatment guidelines do not give a definite upper limit for basal insulin dose, and there may be the temptation to continue with a familiar routine by increasing the basal insulin dose despite the patient still not achieving glycemic targets-a situation known as 'over-basalization' [10]. The aim of basal 
Initiate Basal Insulin

Usually with metformin $+/$ - other noninsulin agent

Start: $10 \mathrm{U} /$ day or $0.1-0.2 \mathrm{U} / \mathrm{kg} /$ day

Adjust: $10-15 \%$ or 2-4 units once or twice weekly to reach FBG target

For hypo: Determine \& address cause; if no clear reason for hypo,

$\downarrow$ dose by 4 units or $10-20 \%$

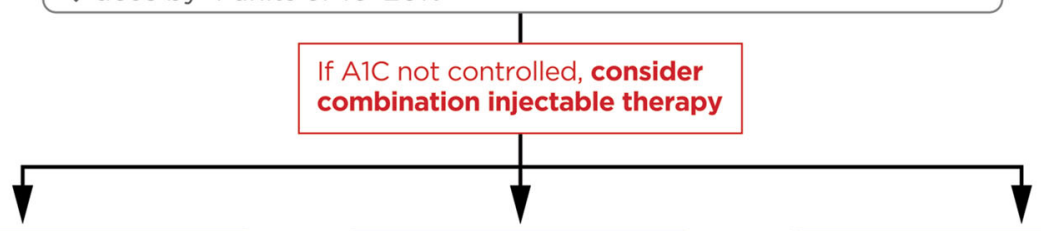

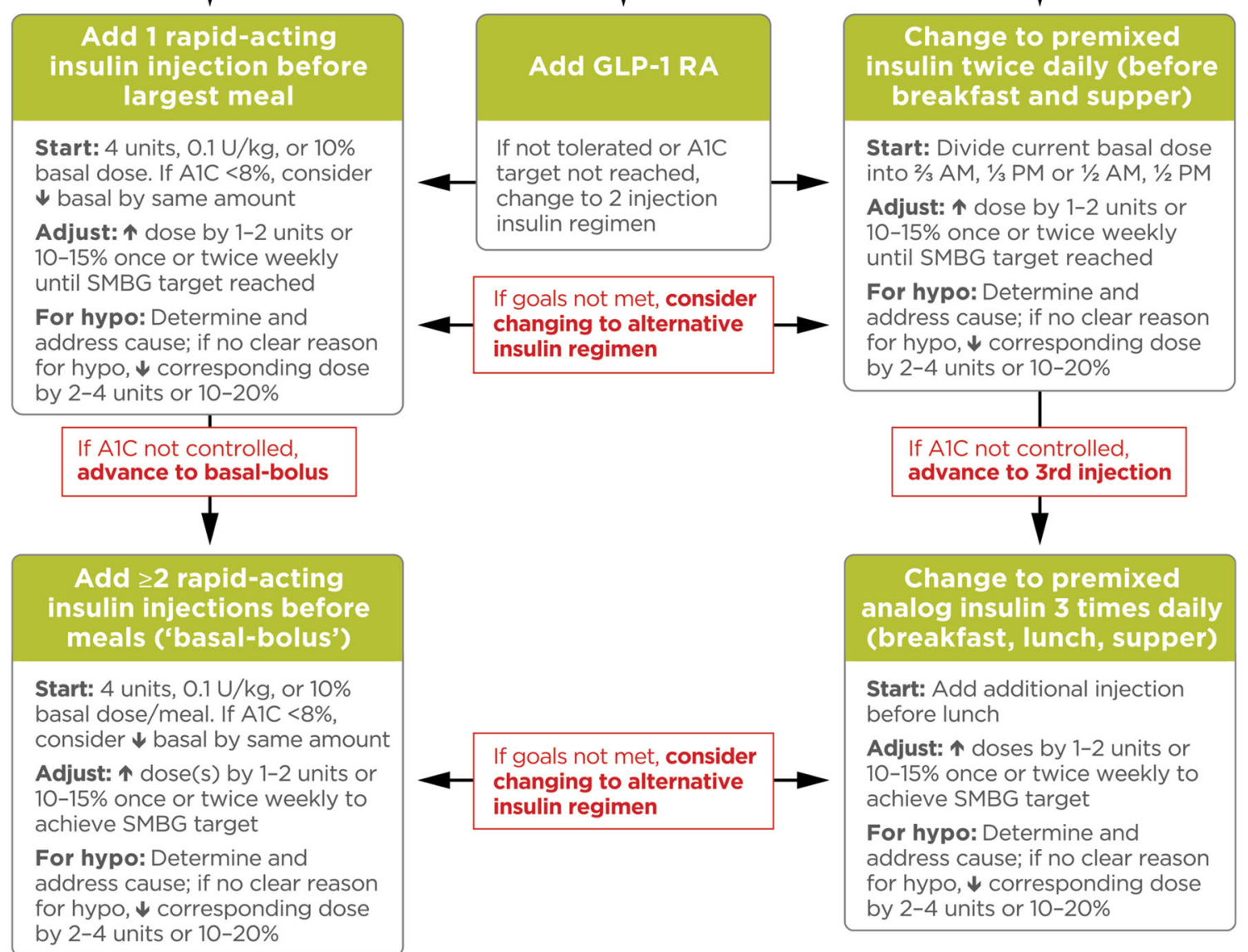

Fig. 1 Combination injectable therapy for type 2 diabetes. $A 1 C$ Glycated hemoglobin (HbAlc), FBG fasting blood glucose, GLP-1 RA glucagon-like peptide-1 receptor agonist, hypo hypoglycemia, $S M B G$ self-monitoring of

insulin treatment to provide a steady level of insulin throughout the day, mimicking normal physiological production and controlling FPG levels; its effects on PPG are limited. In T2D the initial use of basal insulin alone therefore blood glucose. (Adapted with permission from American Diabetes Association 2017 guidelines. Reproduced with permission from Inzucchi et al. [57])

assumes that beta-cell function is still sufficient to help cover increased prandial insulin needs in terms of insulin synthesis and secretion [10]. Data from a recent study suggest that basal insulin has a 'ceiling effect,' whereby reductions 
in FPG become proportionally smaller with increasing dose from 0.3 up to about $0.5 \mathrm{U} / \mathrm{kg}$ body weight (BW)/day, at which point FPG response does not increase despite increasing insulin levels [11]. Another study suggests that increasing basal insulin above 0.5 Units $/ \mathrm{kg}$ BW/day may not improve glycemic control and may also result in weight gain and increased risk of hypoglycemia [12]. It is therefore important to keep in mind (1) the risk of over-basalization and (2) guideline recommendations that basal insulin therapy should be escalated to combination injectables when the basal insulin dose exceeds 0.5 Units/kg BW/day.

\section{BEYOND BASAL INSULIN}

When treatment is intensified beyond basal insulin therapy, a number of factors should be taken into account as part of the shared decisionmaking process, such as patient preference, safety, tolerability, glycemic efficacy, risk of hypoglycemia, and other non-glycemic effects (e.g., weight change and/or impact on life-style) [13]. Continued basal insulin therapy should, however, be considered an essential component of future treatment strategies [2]. Initial discussions should also include issues around lifestyle (nutrition, weight loss, and physical activity) and the possible treatment of obesity, such as using the American Association of Clinical Endocrinologists Obesity Treatment Algorithm, which may include obesity pharmacotherapy [14]. The effectiveness of lifestyle changes such as weight loss and exercise in decreasing the incidence and progression of T2D is well known. Although generally considered an initial strategy, it is important that lifestyle optimization is ongoing throughout the course of T2D [3]. In a cohort study, almost half of overweight or obese patients with T2D who lost a mean of $4 \%$ of body weight were able to reduce their insulin dose; a mean reduction of $11 \%$ of initial body weight was required to discontinue insulin [15]. Although exercise has undoubted benefits for patients with $\mathrm{T} 2 \mathrm{D}$, those using insulin or insulin secretagogues should be made aware of the amplified risk of hypoglycemia during and after exercise and should be advised on blood-glucose monitoring, reductions in insulin dose, and/or carbohydrate supplementation [16].

Efforts to improve lifestyle, however, should not delay changes in therapy; such changes can be done simultaneously and adjusted based on patient response to lifestyle efforts [3]. Therapeutically, there are two main guideline-recommended options for escalating basal insulin therapy [2, 3]. The first is to add a prandial insulin to the treatment regimen, either by adding a RAI prior to the largest meal of the day, with addition at other meals in stages if required (basal-plus), adding RAI at all meals (basal-bolus), or by switching to a premixed (biphasic) insulin formulation of intermediateand short-acting insulins. In general, RAIs are preferred over regular human insulin because of their more rapid onset and offset of action and association with a lower incidence of hypoglycemia [2, 3], although regular insulin may represent a pragmatic choice where costs or lack of resources limit availability [17]. The second option is to add a GLP-1 RA to the treatment regimen. Each treatment regimen has advantages and disadvantages (Table 1), and these should be taken into account when deciding on a strategy with the patient.

\section{ADDING PRANDIAL INSULIN}

The aim of injecting RAIs just before a meal is to support basal-insulin action on FPG by controlling PPG excursions. In effect, adding prandial RAIs to the treatment regimen mimics the physiological meal-simulated insulin release, which is lost first as beta-cell function declines. RAI analogs (lispro, aspart, or glulisine) are preferred over regular human insulin because they have a more rapid onset and shorter duration of action, making them better suited for controlling PPG, and are associated with less hypoglycemia $[18,19]$. The simplest and generally most effective way of adding prandial to basal insulin is to cover the largest (or most carbohydrate-heavy) meal of the day with an injection of RAI, often termed basal-plus $[7,13]$. The initial mealtime dose of RAI should be $4 \mathrm{U}$, $0.1 \mathrm{U} / \mathrm{kg} \mathrm{BW}$, or $10 \%$ of the basal dose (possibly with a reduction in basal insulin dose by the 
Table 1 Advantages and disadvantages of prandial insulin and glucagon-like peptide-1 receptor agonist regimens for insulin intensification

\begin{tabular}{|c|c|c|}
\hline $\begin{array}{l}\text { Guideline- } \\
\text { recommended } \\
\text { options }\end{array}$ & Advantages & Disadvantages \\
\hline \multicolumn{3}{|l|}{ Prandial insulin } \\
\hline Basal-plus & $\begin{array}{l}\text { Dosing/titration flexibility greater than basal- } \\
\text { bolus or premixed } \\
\text { Gradual introduction to multiple daily } \\
\text { injections }\end{array}$ & $\begin{array}{l}\text { Risk of hypoglycemia } \\
\text { Weight gain } \\
\text { Progresses to multiple daily injections }\end{array}$ \\
\hline Basal-bolus & $\begin{array}{l}\text { Dosing/titration flexibility greater than } \\
\text { premixed }\end{array}$ & $\begin{array}{l}\text { Multiple daily injections immediately } \\
\text { Risk of hypoglycemia } \\
\text { Weight gain }\end{array}$ \\
\hline Premixed & Simplified regimen vs. basal-plus of basal-bolus & $\begin{array}{l}\text { Less flexibility than basal plus or basal bolus } \\
\text { Less effective glycemic control vs. basal-plus of basal- } \\
\text { bolus } \\
\text { Greater risk of hypoglycemia and weight gain }\end{array}$ \\
\hline \multicolumn{3}{|l|}{ GLP-1 RAs } \\
\hline $\begin{array}{l}\text { Added to basal } \\
\text { insulin }\end{array}$ & $\begin{array}{l}\text { Weight neutral/weight loss } \\
\text { Lower incidence of hypoglycemia vs. addition } \\
\text { of RAI }\end{array}$ & $\begin{array}{l}\text { Once/twice daily or once weekly (depending on GLP-1 } \\
\text { RA) injection in addition to basal insulin } \\
\text { Gastrointestinal side effects }\end{array}$ \\
\hline $\begin{array}{l}\text { Fixed-ratio } \\
\text { combination }\end{array}$ & $\begin{array}{l}\text { Simple, once-daily regimen } \\
\text { Decreased post-prandial glucose excursions } \\
\text { without increased risk of hypoglycemia } \\
\text { Reduced gastrointestinal side effects vs. GLP-1 } \\
\text { RA alone } \\
\text { Reduced weight gain vs. basal insulin }\end{array}$ & Gastrointestinal side effects \\
\hline
\end{tabular}

GLP-1 RA glucagon-like peptide-1 receptor agonist, $R A I$ rapid-acting insulin

same amount in patients with a HbA1c level of $<8 \%$ [64 $\mathrm{mmol} / \mathrm{mol}]$ ) [2]. The dose should be titrated by $1-2$ U or $10-15 \%$ every $2-3$ days until targets are met (e.g., 2-h PPG or next pre-meal glucose is consistently $>140 \mathrm{mg} / \mathrm{dL}$ ) [3]. If targets are not achieved, additional RAI should be added at one and then two other mealtimes (basal-bolus) as required, with titration as for the initial RAI $[2,3,18]$. This technique has the benefit of a relatively simple, gradual, and structured titration, which may improve confidence with and acceptance of an increasing need for multiple daily injections and may also reduce the incidence of hypoglycemia compared with going straight to basal-bolus therapy [20].

RAI can also be introduced by moving straight to a basal-bolus regimen; in this case, guidelines recommend an initial dose of 50\% basal $/ 50 \%$ prandial daily, split over three doses given before meals, with titration as for basalplus [3]. There is a risk of hypoglycemia during titration of basal-plus and basal-bolus regimens, and patients should be made fully aware of this 
risk and any reported symptoms correlated with blood-glucose logs. If hypoglycemia does occur, the total daily basal and/or prandial insulin dose should be reduced by $10-20 \%$ if the blood glucose level was $<70 \mathrm{mg} / \mathrm{dL}$, or by $20-40 \%$ if the patient experiences severe hypoglycemia (i.e., needed assistance from another person, or blood glucose level is $<40 \mathrm{mg} / \mathrm{dL}$ ) [3]. For some patients, multiple daily injections are inconvenient and may be difficult to manage. The use of complex treatment regimens has been shown to be associated with intentional and accidental nonadherence with medications in patients with T2D $[21,22]$. Premixed (or biphasic) insulins (NPH/regular 70/30; 70/30 aspart mix; $75 / 25$ or $50 / 50$ lispro mix) provide less dosing flexibility but do offer the advantage of a simplified dosing regimen compared with basalbolus [3], which may make them particularly suitable for selected patients, such as those who struggle to manage multiple daily injections [23]. Overall, however, premixed insulins are less effective than basal-bolus regimens in achieving the target HbA1c [23], and their use has been associated with a higher rate of hypoglycemia and with greater weight gain $[3,24]$. The initial premix dose should be based on the current basal insulin dose, divided either into two-thirds AM and one-third PM, or onehalf AM and one-half PM, with once- or twiceweekly titration [1-2 U or 10-15\%) to target. The dose should be reduced by $2-4$ U or $10-20 \%$ if hypoglycemia occurs [2]. Patients taking premixed insulins need to adhere to a regular meal and exercise schedule to reduce the risk of hypoglycemia [23].

\section{ADDING GLP-1 RAS}

Combining drugs with complementary mechanisms of action to target multiple aspects of disease pathophysiology has the potential to improve efficacy. Both insulin and GLP-1 RAs are in themselves effective glucose-lowering therapies, but they achieve this by different, and complimentary, mechanisms of action. The aim of basal insulin therapy is to provide consistent insulin levels to mimic the constant physiological release of insulin that regulates endogenous glucose levels. Basal insulin acts in a non-glucose-dependent manner predominantly on FPG levels, with a lesser effect on PPG. Treatment with insulin is generally associated with an increase in body weight and a risk of hypoglycemia [2, 25]. GLP-1 RAs act on both FPG and PPG levels, to varying degrees, by enhancing glucose-dependent insulin secretion by beta-cells and decreasing glucagon secretion by alpha-cells [26]. In addition, they have been shown to inhibit gastric acid secretion, slow gastric emptying, and, by interactions with the central nervous system, increase satiety, resulting in reduced food intake and therefore reduced glucose input $[26,27]$. There are two general types of GLP-1 RAs, namely, short- and long-acting [26, 28]. Short-acting GLP-1 RAs (e.g., exenatide, lixisenatide) have a more profound effect on PPG than long-acting agents (e.g., liraglutide, albiglutide) and are associated with a slower, more sustained effect on gastric emptying. Long-acting agents have a greater effect on FPG than on PPG and a lesser effect on gastric emptying which seems to be subjected to tachyphylaxis [2, 28]. Treatment with GLP-1 RAs is generally associated with weight loss due to appetite suppression. This may make them particularly suitable for patients who are already overweight or those who fear weight gain with additional insulin therapy.

Exenatide and liraglutide have been associated with slight increases in heart rate $(<2$ beats/min) [29]. The mechanism behind these increases in heart rate, but it is interesting to note that the effect appears to be more evident for long-acting GLP-1 RAs (liraglutide, exenatide long-acting release) than for short-acting ones (exenatide twice daily) [30], and with liraglutide compared with lixisenatide [31]. Overall, GLP-1 RAs as a class have demonstrated positive cardiovascular outcomes, with metaanalyses of clinical trial data showing no significant differences or demonstrating improvements in the rates of major cardiovascular events between GLP-1 RAs and placebo or comparator drugs $[32,33]$. Since 2008, the U.S. Food and Drug Administration (FDA) has required that all antidiabetes medications demonstrate cardiovascular safety [34]. To date, the results of four cardiovascular outcome trials 
of GLP-1 RAs have been reported, all of which have demonstrated at least noninferiority of treatment with GLP-1RAs compared with standard care $[35,36]$, even though a direct comparison between studies is difficult due to different patient populations, length of trials, dropout rates, and HbA1c lowering. The ELIXA study of lixisenatide showed that in patients with T2D who have had a recent acute coronary event (within 180 days), lixisenatide was noninferior to placebo regarding primary endpoint events, with no significant differences in rate of hospitalization for heart failure or rate of death between the groups [37]. Even though there was a very large dropout rate, similar findings were reported in the EXSCEL trial in patients with or without previous cardiovascular disease, with no difference in major cardiovascular events with extended-release exenatide compared with placebo [36]. In the LEADER trial of liraglutide in patients with T2D and high cardiovascular risk, primary outcome, death from cardiovascular causes, and death from any cause, occurred in significantly fewer liraglutide-treated patients than in those on placebo, with no significant differences in rates of nonfatal myocardial infarction, nonfatal stroke, and hospitalization for heart failure between groups [38]. The SUSTAIN-6 trial, which also included patients at high cardiovascular risk, reported significant reductions in major cardiovascular events with semaglutide, largely driven by a reduced incidence of nonfatal stroke [36], even though the trail was not pre-specified as a superiority trial.

The most commonly reported side effects of GLP-1 RA therapy are gastrointestinal ones (nausea, vomiting, and diarrhea). These are generally mild to moderate and typically improve over time, resulting in discontinuation of therapy in $<5 \%$ of patients in clinical trials; slow dose-titration helps to reduce these effects [28]. Concerns have been expressed regarding the possible association between treatment with GLP-1 RA and acute pancreatitis and/or pancreatic cancer, based on a series of case reports $[39,40]$; however, no studies have confirmed that GLP-1 RAs cause pancreatitis [41], and no evidence of an increased risk was found in a large systematic review and meta-analysis [42].
Furthermore, a recent FDA and European Medicines Agency assessment of evidence from clinical trials and observational studies concluded that 'assertions concerning a causal association between incretin-based drugs (i.e., GLP-1 RAs and dipeptidyl peptidase 4 inhibitors) and pancreatitis or pancreatic cancer, as expressed recently in the scientific literature and in the media, are inconsistent with the current data' [43]. The rates of pancreatitis and pancreatic cancer have been generally low in large long-term CVOT trials. For example, in the ELIXA study in 6068 patients with T2D, pancreatitis occurred in five lixisenatide- and eight placebo-treated patients, and three lixisenatideand nine placebo-treated patients were diagnosed with pancreatic cancer [37]. In the SUSTAIN-6 trial including 3297 patients, acute pancreatitis occurred in nine patients in the semaglutide group and in 12 in the placebo group; pancreatic cancer occurred in one and four patients, respectively [38]. Similarly, fewer patients treated with liraglutide in the LEADER trial experienced acute pancreatitis compared with placebo (18 vs. 23 patients, respectively), although the incidence of pancreatic cancer was greater in the liraglutide group (13 vs. 5 patients, respectively) [40]. In addition, a recent large, multinational cohort study found that the use of incretin-based drugs was not associated with an increased risk of pancreatic cancer compared with sulfonylureas [44]. Nevertheless, guidelines recommend that GLP-1 RAs should be used with caution in patients with a history of pancreatitis and discontinued if acute pancreatitis develops [3].

The effectiveness of GLP-1 RAs combined with basal insulins to treat $\mathrm{T} 2 \mathrm{D}$ has been demonstrated in a large number of clinical trials and in real-world studies [8]. In patients whose T2D is inadequately controlled on basal insulin, the addition of the GLP-1 RAs to the treatment regimen has consistently shown improvements in HbA1c and PPG excursions, with reductions in body weight, but without an increase in hypoglycemic risk compared with placebo [45-47] and RAIs (basal-plus and basal-bolus) $[6,8,48]$. GLP-1 RAs are administered via subcutaneous injection, with dosing varying depending on the agent (e.g., exenatide: twice 
Table 2 Randomized trials of fixed-ratio insulin/glucagon-like peptide-1 receptor agonist combinations

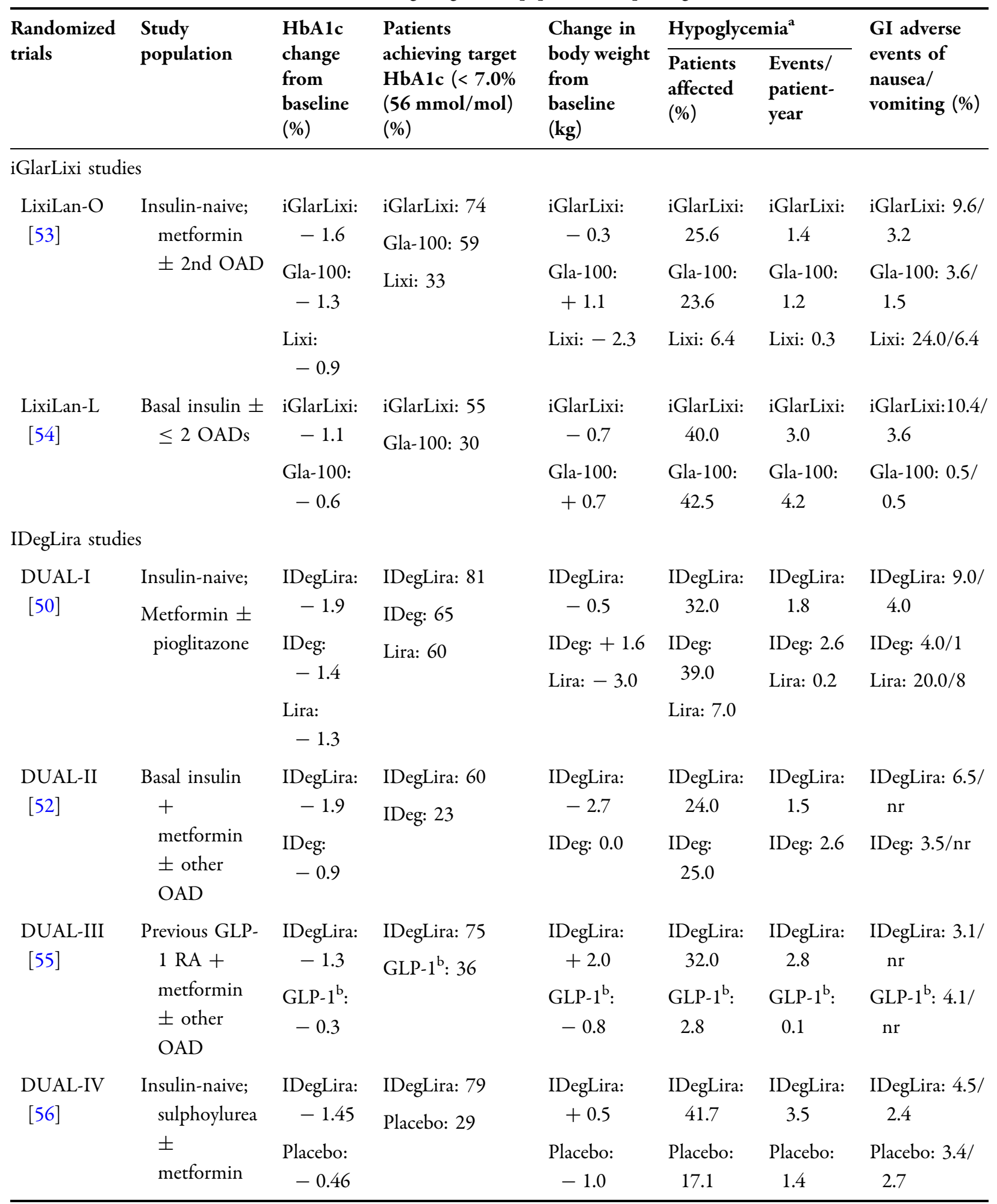


Table 2 continued

\begin{tabular}{|c|c|c|c|c|c|c|c|}
\hline \multirow{2}{*}{$\begin{array}{l}\text { Randomized } \\
\text { trials }\end{array}$} & \multirow{2}{*}{$\begin{array}{l}\text { Study } \\
\text { population }\end{array}$} & \multirow{2}{*}{$\begin{array}{l}\text { HbAlc } \\
\text { change } \\
\text { from } \\
\text { baseline } \\
(\%)\end{array}$} & \multirow{2}{*}{$\begin{array}{l}\text { Patients } \\
\text { achieving target } \\
\text { HbAlc }(<7.0 \% \\
(56 \mathrm{mmol} / \mathrm{mol}) \\
(\%)\end{array}$} & \multirow{2}{*}{$\begin{array}{l}\text { Change in } \\
\text { body weight } \\
\text { from } \\
\text { baseline } \\
(\mathrm{kg})\end{array}$} & \multicolumn{2}{|c|}{ Hypoglycemia $^{a}$} & \multirow{2}{*}{$\begin{array}{l}\text { GI adverse } \\
\text { events of } \\
\text { nausea/ } \\
\text { vomiting (\%) }\end{array}$} \\
\hline & & & & & $\begin{array}{l}\text { Patients } \\
\text { affected } \\
(\%)\end{array}$ & $\begin{array}{l}\text { Events/ } \\
\text { patient- } \\
\text { year }\end{array}$ & \\
\hline \multirow[t]{2}{*}{$\begin{array}{l}\text { DUAL-V } \\
{[51]}\end{array}$} & $\begin{array}{l}\text { Gla-100 }+ \\
\text { metformin }\end{array}$ & $\begin{array}{c}\text { IDegLira: } \\
-1.8\end{array}$ & $\begin{array}{l}\text { IDegLira: } 72 \\
\text { Gla-100: } 47\end{array}$ & $\begin{array}{l}\text { IDegLira: } \\
-1.4\end{array}$ & $\begin{array}{l}\text { IDegLira: } \\
28.4\end{array}$ & $\begin{array}{l}\text { IDegLira: } \\
2.2\end{array}$ & $\begin{array}{l}\text { IDegLira: 9.4/ } \\
\mathrm{nr}\end{array}$ \\
\hline & & $\begin{array}{l}\text { Gla-100: } \\
\quad-1.1\end{array}$ & & $\begin{array}{c}\text { Gla-100: } \\
+1.8\end{array}$ & $\begin{array}{l}\text { Gla-100: } \\
49.1\end{array}$ & $\begin{array}{l}\text { Gla-100: } \\
5.1\end{array}$ & $\begin{array}{l}\text { Gla-100: } 1.1 / \\
\mathrm{nr}\end{array}$ \\
\hline
\end{tabular}

GI Gastrointestinal, Gla-100 insulin glargine $100 \mathrm{U}$, HbAlc glycated hemoglobin A1c, IDeg insulin degludec, Lira liraglutide, Lixi lixisenatide, $n r$ not reported, $O A D$ oral antidiabetes drug

a DUAL studies: confirmed or severe hypoglycemia $(<56 \mathrm{mg} / \mathrm{dL})$; LixiLan studies: documented symptomatic hypoglycemia $(\leq 70 \mathrm{mg} / \mathrm{dL})$

${ }^{\mathrm{b}}$ Unchanged from previous therapy

daily before meals; liraglutide: once daily [independent of meals]; lixisenatide: once daily [within $1 \mathrm{~h}$ before any meal of the day]; exenatide extended-release, albiglutide, and dulaglutide: once weekly) [49].

A benefit of GLP-1 RAs in terms of the patient's perspective is that these are not insulin preparations, and therefore the patient may not have the negative perceptions of weight gain and hypoglycemia. The positive effects of GLP-1 RAs on both of these parameters may be seen as a particular benefit by some patients. The sideeffect profile, particularly the risk of gastrointestinal effects, may be a concern for some patients, but these can be ameliorated by slow, controlled dose escalation. More regular bloodglucose monitoring during titration can also help further reduce the likelihood of hypoglycemia and can be reassuring for patients with a particular fear of this complication.

\section{BASAL INSULIN/GLP-1 RA FIXED- RATIO COMBINATIONS}

Adding a GLP-1 RA to basal insulin as a separate treatment adds to the injection burden and regimen complexity for patients (although to a lesser degree than basal-bolus regimens), as well as potentially introducing GI adverse events.
Recently, two new titratable fixed-ratio combination (FRC) formulations of a basal insulin and a GLP-1 RA have been approved by the FDA for the treatment of adults with T2D. iGlarLixi is a FRC of insulin glargine 100 Units/ml (iGlar) and the short-acting GLP-1 RA lixisenatide (Lixi). IDegLira is an FRC of insulin degludec (IDeg) in combination with the long-acting GLP-1 RA liraglutide (Lira). In clinical trials, both FRCs have been shown to result in greater reductions in HbA1c compared with either basal insulins or GLP-1 RAs given alone, with the benefit of mitigation of weight loss without a higher risk of hypoglycemia compared with basal insulin alone [50-57] (Table 2). In insulin-experienced patients, iGlarLixi resulted in greater reductions in $\mathrm{HbA} 1 \mathrm{c}$ from baseline compared with insulin glargine $(-1.1 \%$ vs. $-0.6 \%, \mathrm{p}<0.0001)$, with a greater proportion of patients achieving HbA1c $<7.0 \%$ (53 $\mathrm{mmol} / \mathrm{mol}$ ) (55\% vs. $30 \%$, respectively) [54]. Mean body weight decreased by 0.7 $\mathrm{kg}$ with iGlarLixi and increased by $0.7 \mathrm{~kg}$ with iGlar. Rates of documented symptomatic hypoglycemia ( $\mathrm{PG} \leq 70 \mathrm{mg} / \mathrm{dL}$ ) were similar between groups $(40.0 \%$ in the iGlarLixi group and $42.5 \%$ in the iGlar group) [54].

Similar results were achieved using IDegLira. Insulin-experienced patients treated with IDegLira showed greater reductions in HbA1c compared with insulin degludec alone ( -1.9 vs. 
$-0.9 \%$, respectively; $\mathrm{p}<0.0001$ ) [50] or insulin glargine alone $(-1.8$ vs. -1.1 , respectively; $\mathrm{p}<$ 0.001) [56]. Treatment with IDegLira was also associated with weight loss compared with weight gain/no change with basal insulin alone ( $-2.7 \mathrm{~kg}$ vs. no change with insulin degludec; $-1.4 \mathrm{~kg}$ vs. $+1.8 \mathrm{~kg}$ with insulin glargine). Rates of confirmed hypoglycemia with IDegLira were similar to insulin degludec alone $(36-51 \%$, and lower than with insulin glargine alone (45-57\%) [54]. Interestingly, the use of a FRC appears to mitigate the side effects of its individual components, with a reduction in gastrointestinal side effects compared with the GLP-1 RA component alone due to slow titration $[50,53,54,58]$. For example, in the LixiLan-O trial, $9.6 \%$ of patients treated with iGlarLixi experienced nausea, the most commonly reported gastrointestinal event, compared with $24.0 \%$ of patients treated with Lixi alone [53]. Similarly, in the DUAL-1 trial, nausea was experienced by $9 \%$ of patients treated with IDegLira compared with $20 \%$ of those treated with Lira alone [50].

Titration of basal insulin/GLP-1 RA FRCs is based on the insulin component, and follows a similar titration schedule for that used for titrating insulin. It is important to note that these are fixed-ratio, not fixed-dose combinations; iGlarLixi is approved in a 100 Units iGlar:33 $\mu$ g lixisenatide ratio combination and IDegLira a 100 Units IDeg:3.6 mg liraglutide ratio combination. Both components are titrated based on the patient's insulin needs, with the GLP-1 RA component rising in ratio with the insulin dose, at an amount depending on the formulation.

iGlarLixi is supplied premixed in a modified SoloStar pen [59], which contains a fixed ratio of 100 Units of iGlar to $33 \mu \mathrm{g}$ of lixisenatide (doses range from 15 Units/5 $\mu$ g to 60 Units/20 $\mu \mathrm{g}$ of iGlar/lixisenatide); only the insulin dose is shown in the pen window. iGlarLixi is administered subcutaneously once daily within 1 hour before the first meal of the day. Patients who are switching to iGlarLixi from a basal insulin analog should stop their current insulin, and their iGlarLixi dose should be calculated from their current insulin dose. For those switching from basal insulin where the insulin dose is $<30$
Units, the starting dose should be 15 Units; where the insulin dose is 30-60 Units, starting dose should be 30 Units. iGlarLixi should be titrated to individualized FPG goals, with dose adjustments of 2-4 Units every week as required based on the patient's metabolic needs, blood glucose monitoring results, and glycemic control goal. The maximum dose of iGlarLixi is 60 Units/20 $\mu$ g; for those patients requiring $>60$ Units alternative separate antidiabetes products such as iGlar and lixisenatide should be used.

For IDegLira, the pre-filled pen shows dose steps, equivalent to units of insulin; each dose step consists of 1 Unit of insulin degludec and $0.036 \mathrm{mg}$ liraglutide. The pre-filled pen can provide from 1 up to 50 dose steps in one injection, in increments of one dose step. IDegLira can be administered, once daily, at any time but at the same time each day, and does not need to be used with a meal. Patients who are switching to IDegLira from a basal insulin analog should stop using their current insulin, and all patients should initiate treatment with 16 Units (16 Units of insulin degludec and 0.58 $\mathrm{mg}$ of liraglutide) regardless of whether they were previously receiving basal insulin. Dose adjustments should be made based on target FPG, with the dose being titrated upwards or downwards by 2 Units every 3-4 days. The maximum dose of IDegLira is 50 dose steps (50 Units insulin degludec and $1.8 \mathrm{mg}$ liraglutide); patients requiring $>60$ Units would need to administer separate injections of IDeg and liraglutide. IDegLira currently carries a blackbox warning for risk of thyroid c-cell tumors related to liraglutide, and is contraindicated in patients with a personal or family history of medullary thyroid carcinoma and in patients with multiple endocrine neoplasia syndrome type 2 .

\section{ACKNOWLEDGEMENTS}

Funding. This study was funded by Sanofi US, Inc. including funding of the journal's article processing charge. 
Medical Writing Assistance. The author received writing and editorial support in the preparation of this manuscript provided by Rasilaben Vaghjiani, PhD, of Excerpta Medica, funded by Sanofi US, Inc.

Authorship. The named author meets the International Committee of Medical Journal Editors (ICMJE) criteria for authorship for this article, takes responsibility for the integrity of the work as a whole, and has given his approval for this version to be published. The author had full access to all of the data in this study and takes complete responsibility for the integrity of the data and accuracy of the data analysis.

Disclosures. Jerry Meece is a consultant for Astra Zeneca, Eli Lilly, Johnson and Johnson, Novo Nordisk, and Sanofi.

Compliance with Ethics Guidelines. This article is based on previously conducted studies and does not contain studies with human participants or animals performed by the author.

Data Availability. Data sharing is not applicable in this article as no datasets were generated or analyzed during the current study.

Open Access. This article is distributed under the terms of the Creative Commons Attribution-NonCommercial 4.0 International License (http://creativecommons.org/ licenses/by-nc/4.0/), which permits any noncommercial use, distribution, and reproduction in any medium, provided you give appropriate credit to the original author(s) and the source, provide a link to the Creative Commons license, and indicate if changes were made.

\section{REFERENCES}

1. International Diabetes Federation. IDF diabetes atlas. Eighth edition 2017. http://www. diabetesatlas.org/resources/2017-atlas.html. Accessed 3 Jan 2018.

2. American Diabetes Association. Standards of medical care in diabetes-2017: pharmacologic approaches to glycemic treatment. Diabetes Care. 2017;40[Suppl 1]:S64-74.

3. Garber AJ, Abrahamson MJ, Barzilay JI, et al. Consensus statement by the American Association of Clinical Endocrinologists and American College of Endocrinology on the comprehensive type 2 diabetes management algorithm-2017 executive summary. Endocr Pract. 2017. https://doi.org/10. 4158/ep161682.cs.

4. Gill GV, Yudkin JS, Keen H, Beran D. The insulin dilemma in resource-limited countries. A way forward? Diabetologia. 2011;54:19-24.

5. Diamant M, Nauck MA, Shaginian R, 4B Study Group, et al. Glucagon-like peptide 1 receptor agonist or bolus insulin with optimized basal insulin in type 2 diabetes. Diabetes Care. 2014;37:2763-73.

6. Mathieu C, Rodbard HW, Cariou B, et al. A comparison of adding liraglutide versus a single daily dose of insulin aspart to insulin degludec in subjects with type 2 diabetes (BEGIN: VICTOZA ADDON). Diabetes Obes Metab. 2014;16:636-44.

7. Eng C, Kramer CK, Zinman B, Retnakaran R. Glucagon-like peptide-1 receptor agonist and basal insulin combination treatment for the management of type 2 diabetes: a systematic review and meta-analysis. Lancet. 2014;384:2228-34.

8. Rosenstock J, Guerci B, Hanefeld M, et al. Prandial options to advance basal insulin glargine therapy: testing lixisenatide plus basal insulin versus insulin glulisine either as basal-plus or basal-bolus in type 2 diabetes: the GetGoal Duo-2 trial. Diabetes Care. 2016;39:1318-28.

9. Balena R, Hensley IE, Miller S, Barnett AH. Combination therapy with GLP-1 receptor agonists and basal insulin: a systematic review of the literature. Diabetes Obes Metab. 2013;15:485-502.

10. LaSalle JR, Berria R. Insulin therapy in type 2 diabetes mellitus: a practical approach for primary care physicians and other health care professionals. J Am Osteopath Assoc. 2013;113:152-62.

11. Shaefer C, Traylor L, Gao L, Dex T, Sepe P, Skolnik N. Exploratory study of a dose-response curve for basal insulin. Presented at 75th Scientific Sessions of the American Diabetes Association. Boston MA. June 5-9, 2015.

12. Reid T, Gao L, Gill J, et al. How much is too much? Outcomes in patients using high-dose insulin glargine. Int J Clin Pract. 2016;70:56-65.

13. Nathan DM, Buse JB, Davidson MB, et al. Medical management of hyperglycemia in type 2 diabetes: a consensus algorithm for the initiation and 
adjustment of therapy a consensus statement of the American Diabetes Association and the European Association for the Study of Diabetes. Diabetes Care. 2009;32:193-203.

14. Garvey WT, Mechanick JI, Brett EM, et al. American Association of Clinical Endocrinologists and American College of Endocrinology comprehensive clinical practice guidelines for medical care of patients with obesity. Endocr Pract. 2016;22(Suppl. 3):1-203.

15. Kumar AA, Palamaner Subash Shantha G, Kahan S, et al. Intentional weight loss and dose reductions of anti-diabetic medications-a retrospective cohort study. PLoS ONE. 2012;7:e32395.

16. Younk LM, Mikeladze M, Tate D, Davis SN. Exercise-related hypoglycemia in diabetes mellitus. Expert Rev Endocrinol Metab. 2011;6:93-108.

17. Kalra S, Gupta Y. Choosing an insulin regime: a developing country perspective. African J Diabetes Manag. 2014;22:17-20.

18. Inzucchi SE, Bergenstal RM, Buse JB, et al. Management of hyperglycemia in type 2 diabetes: a patient-centered approach position statement of the American Diabetes Association (ADA) and the European Association for the Study of Diabetes (EASD). Diabetes Care. 2012;35:1364-79.

19. Hirsch IB. Insulin analogues. $\mathrm{N}$ Eng J Med. 2005;352:174-83.

20. Davidson MB, Raskin P, Tanenberg RJ, Vlajnic A, Hollander P. A stepwise approach to insulin therapy in patients with type 2 diabetes mellitus and basal insulin treatment failure. Endocr Pract. 2011;17:395-403.

21. Peyrot M, Barnett AH, Meneghini LF, SchummDraeger PM. Insulin adherence behaviours and barriers in the multinational Global Attitudes of Patients and Physicians in Insulin Therapy study. Diabet Med. 2012;29:682-9.

22. de Vries ST, Keers JC, Visser R, et al. Medication beliefs, treatment complexity, and non-adherence to different drug classes in patients with type 2 diabetes. J Psychosom Res. 2014;76:134-8.

23. Kalra S, Mukherjee JJ, Venkataraman S, et al. Hypoglycemia: the neglected complication. Indian J Endocrinol Metab. 2013;17:819-34.

24. Giuliano D, Maiorino MI, Bellastella G, et al. Efficacy of insulin analogs in achieving the hemoglobin A1c target of $<7 \%$ in type 2 diabetes: metaanalysis of randomized controlled trials. Diabetes Care. 2011;34:510-7.
25. Holman RR, Thorne KI, Farmer AJ, 4-T Study Group, et al. Addition of biphasic, prandial, or basal insulin to oral therapy in type 2 diabetes. $\mathrm{N}$ Engl J Med. 2007;357:1716-30.

26. Fineman MS, Cirincione BB, Maggs D, Diamant M. GLP-1 based therapies: differential effects on fasting and postprandial glucose. Diabetes Obes Metab. 2012;14:675-88.

27. Kanoski SE, Fortin SM, Arnold M, Grill HJ, Hayes MR. Peripheral and central GLP-1 receptor populations mediate the anorectic effects of peripherally administered GLP-1 receptor agonists, liraglutide and exendin-4. Endocrinology. 2011;152:3103-12.

28. Werner U. Effects of the GLP-1 receptor agonist lixisenatide on postprandial glucose and gastric emptying-preclinical evidence. J Diabetes Complicat. 2014;28:110-14.

29. Prasad-Reddy L, Isaacs D. A clinical review of GLP-1 receptor agonists: efficacy and safety in diabetes and beyond. Drugs Context. 2015;4:212283.

30. Robinson LE, Holt TA, Rees K, Randeva HS, O'Hare JP. Effects of exenatide and liraglutide on heart rate, blood pressure and body weight: systematic review and meta-analysis. BMJ Open. 2013;3:e001986.

31. Nakatani Y, Kawabe A, Matsumura M, et al. Effects of GLP-1 receptor agonists on heart rate and the autonomic nervous system using Holter electrocardiography and power spectrum analysis of heart rate variability. Diabetes Care. 2016;39:e22-3.

32. Marso SP, Lindsey JB, Stolker JM, et al. Cardiovascular safety of liraglutide assessed in a patient-level pooled analysis of phase 2: 3 liraglutide clinical development studies. Diab Vasc Dis Res. 2011;8:237-40.

33. Monami M, Dicembrini I, Nardini C, Fiordelli I, Mannucci E. Effects of glucagon-like peptide-1 receptor agonists on cardiovascular risk: a metaanalysis of randomized clinical trials. Diabetes Obes Metab. 2014;16:38-47.

34. Food and Drug Administration (FDA). Guidance for industry: diabetes mellitus-evaluating cardiovascular risk in new antidiabetic therapies to treat type 2 diabetes [article online], 2008. http://www.fda. gov/downloads/Drugs/GuidanceComplianceRegul atoryInformation/Guidances/ucm071627.pdf). Acc essed 7 Nov 2016.

35. Holman RR, Bethel MA, Mentz RJ, et al. EXSCEL Study Group. Effects of once-weekly exenatide on cardiovascular outcomes in type 2 diabetes. N Engl J Med. 2017;377:1228-39. 
36. Marso SP, Bain SC, Consoli A, Eliaschewitz FG, Jódar E, Leiter LA, Lingvay I, Rosenstock J, Seufert J, Warren ML, Woo V, Hansen O, Holst AG, Pettersson J, Vilsbøll T, SUSTAIN-6 Investigators. Semaglutide and cardiovascular outcomes in patients with type 2 diabetes. $\mathrm{N}$ Engl J Med. 2016;375:1834-44.

37. Pfeffer MA, Claggett B, Diaz R, et al. Lixisenatide in patients with type 2 diabetes and acute coronary syndrome. N Eng J Med. 2015;373:2247-57.

38. Marso SP, Daniels GH, Brown-Frandsen K, et al. Liraglutide and cardiovascular outcomes in type 2 diabetes. N Eng J Med. 2016;375:311-22.

39. Food and Drug Administration (FDA). Exenatide (marketed as BYETTA): acute pancreatitis. postmarketing reviews volume 1 , number 2, 2008b. http://www.fda.gov/Drugs/DrugSafety/DrugSafety Newsletter/ucm119034.htm\#exenatide. Accessed 7 Nov 2016.

40. Elashoff M, Matveyenko AV, Gier B, Elashoff R, Butler PC. Pancreatitis, pancreatic, and thyroid cancer with glucagon-like peptide-1-based therapies. Gastroenterology. 2011;141:150-6.

41. Parks M, Rosebraugh C. Weighing risks and benefits of liraglutide-the FDA's review of a new antidiabetic therapy. N Eng J Med. 2010;362:774-77.

42. Li L, Shen J, Bala MM, et al. Incretin treatment and risk of pancreatitis in patients with type 2 diabetes mellitus: systematic review and meta-analysis of randomised and non-randomised studies. BMJ. 2014;348:g2366.

43. Egan AG, Blind E, Dunder K, et al. Pancreatic safety of incretin-based drugs-FDA and EMA assessment. N Engl J Med. 2014;370:794-97.

44. Azoulay L, Filion KB, Platt RW, et al. Incretin based drugs and the risk of pancreatic cancer: international multicentre cohort study. BMJ. 2016;352:i581.

45. Riddle MC, Aronson R, Home P, et al. Adding oncedaily lixisenatide for type 2 diabetes inadequately controlled by established basal insulin. A 24-week, randomized, placebo-controlled comparison (GetGoal-L). Diabetes Care. 2013;36:2489-96.

46. Riddle MC, Forst T, Aronson R, et al. Adding oncedaily lixisenatide for type 2 diabetes inadequately controlled with newly initiated and continuously titrated basal insulin glargine. A 24-week, randomized, placebo-controlled comparison (GetGoal-Duo 1). Diabetes Care. 2013;36:2497-503.

47. Buse JB, Bergenstal RM, Glass LC, et al. Use of twicedaily exenatide in Basal insulin-treated patients with type 2 diabetes: a randomized, controlled trial. Ann Intern Med. 2011;154:103-12.

48. Rosenstock J, Fonseca VA, Gross JL, et al. Advancing basal insulin replacement in type 2 diabetes inadequately controlled with insulin glargine plus oral agents: a comparison of adding albiglutide, a weekly GLP-1 receptor agonist, versus thrice-daily prandial insulin lispro. Diabetes Care. 2014;37:2317-25.

49. Trujillo JM, Nuffer W, Ellis SL. GLP-1 receptor agonists: a review of head-to-head clinical studies. Ther Adv Endocrinol Metab. 2015;6:19-28.

50. Gough SCL, Bode B, Woo V, et al. Efficacy and safety of a fixed-ratio combination of insulin degludec and liraglutide (IDegLira) compared with its components given alone-results of a phase 3, open-label, randomised, 26-week, treat-to-target trial in insulin-naïve patients with type 2 diabetes. Lancet Diabetes Endocrinol. 2014;2:885-93.

51. Lingvay I, Pérez Manghi F, García-Hernández P, et al. Effect of insulin glargine up-titration vs insulin degludec/liraglutide on glycated haemoglobin in patients with uncontrolled type 2 diabetes: the DUAL randomized clinical trial. JAMA. 2016;315:898-907.

52. Buse JB, Vilsbøll T, Thurman J, et al. Contribution of liraglutide in the fixed-ratio combination of insulin degludec and liraglutide (IDegLira). Diabetes Care. 2014;37:2926-33.

53. Rosenstock J, Aronson R, Grunberger G, et al. Benefits of lixiLan, a titratable fixed-ratio combination of insulin glargine plus lixisenatide, versus insulin glargine and lixisenatide monocomponents in type 2 diabetes inadequately controlled with oral agents: the lixiLan-O randomized trial. Diabetes Care. 2016;39:2026-35.

54. Aroda VR, Rosenstock J, Wysham C, et al. Efficacy and safety of lixiLan, a titratable fixed-ratio combination of insulin glargine plus lixisenatide in type 2 diabetes inadequately controlled on basal insulin and metformin: the lixiLan-L randomized trial. Diabet Care. 2016;39:1972-80.

55. Linjawi S, Bode BW, Chaykin LB, et al. The efficacy of IDegLira (insulin degludec/liraglutide combination) in adults with type 2 diabetes inadequately controlled with a GLP-1 receptor agonist and oral therapy: DUAL III Randomized Clinical Trial. Diabetes Ther. 2017;8(1):101-14. https://doi.org/10. 1007/s13300-016-0218-3.

56. Rodbard HW, Bode BW, Harris SB, et al. Safety and efficacy of insulin degludec/liraglutide (IDegLira) added to sulphonylurea alone or to sulphonylurea and metformin in insulin-naïve people with Type 2 
diabetes: the DUAL IV trial. Diabet Med. 2017;34:189-96.

57. Food and Drug Administration (FDA). Briefing document May 2016. https://www.fda.gov/ downloads/AdvisoryCommittees/CommitteesMeet ingMaterials/Drugs/EndocrinologicandMetabolicD rugsAdvisoryCommittee/UCM502076.pdf. Accessed 12 Feb 2018.

58. Gough SC, Bode BW, Woo VC, et al. One-year efficacy and safety of a fixed combination of insulin degludec and liraglutide in patients with type 2 diabetes: results of a 26-week extension to a 26-week main trial. Diabetes Obes Metab. 2015;17:965-73.

59. SOLIQUA. Prescribing Information (PI). http:// www.accessdata.fda.gov/drugsatfda_docs/label/201 6/208673s000lbl.pdf. Accessed 5 Jan 2017. 